\title{
LÂM SÀNG, CẦN LÂM SÀNG VÀ CHỨC NĂNG HÔ HẤP CỦA TRẺ HEN PHÊ QUẢN CÓ NGƯNG THỞ TÁC NGHẼN KHI NGỦ
}

\author{
Nguyễn Ngọc Quỳnh Lề ${ }^{1, \bigotimes}$, Thục Thanh Huyền², Lê Quỳnh $\mathrm{Chi}^{2}$, Lê Huyền Trang ${ }^{2}$, \\ Nguyễn Thị Diệu Thúy ${ }^{1}$, Nguyễn Thị Thanh Mai ${ }^{1}$, Dương Quý Sỹ ${ }^{4,5}$ \\ ${ }^{1}$ Trường Đại học Y Hà Nội \\ ${ }^{2}$ Bệnh viện Nhi Trung ương \\ ${ }^{3}$ Trường Cao đẳng Y tế Lâm Đồng \\ ${ }^{4}$ Trường Đại học Y khoa Penn State, Hoa kỳ
}

Hội chứng ngưng thở tắc nghẽn khi ngủ và hen phế quản là tình trạng viêm mạn tính đường thở, liên quan với nhau về cơ chế bệnh sinh và có tác động qua lại lẫn nhau. Chúng tôi tiến hành nghiên cứu mô tả cắt ngang trên 54 trẻ hen phế quản từ 6- 17 tuổi tại Bệnh viện Nhi Trung ương nhằm xác định tỷ lệ ngưng thở tắc nghẽn khi ngủ ở trẻ hen và mô tả đặc điểm lâm sàng, cận lâm sàng của nhóm trẻ trên. Chẩn đoán ngưng thở tắc nghẽn khi ngủ bằng đa ký hô hấp. 29/54 (53,7\%) trẻ hen tuổi trung bình 8,38 tuổi có ngưng thở tắc nghẽn khi ngủ, trong đó 26/29

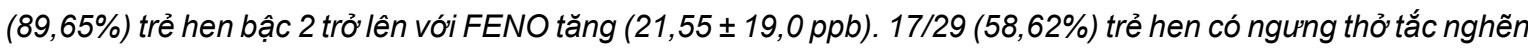
khi ngủ nhẹ, trẻ hen bậc 3 có tỷ lệ ngưng thở tắc nghẽn khi ngủ trung bình cao hơn có ý nghĩa thống kê (41,38\% và $13,79 \%, p<0,05)$. Cần quan tâm đến chẩn đoán ngưng thở tắc nghẽn khi ngủ ở bệnh nhân hen phế quản.

Từ khóa: Hen, OSAS, FENO, trẻ em.

\section{I. ĐẠT VÁN ĐÈ}

Chiến lược toàn cầu phòng chống hen phế quản (GINA) định nghĩa hen phế quản (HPQ) là một bệnh viêm mạn tính đường thở, đặc trưng bởi sự các triệu chứng hô hấp như khò khè, khó thở, nặng ngực và ho. Theo số liệu của Tổ chức $Y$ tế Thế giới, tỷ lệ $\mathrm{HPQ}$ ở trẻ em là 10$12 \%$ và có xu hướng gia tăng, nhất là ở các nước Châu Á - Thái Bình Dương. ${ }^{1}$

Hội chứng ngưng thở tắc nghẽn khi ngủ (OSAS) là sự hiện tượng tắc nghẽn lặp đi lặp lại một phần hay hoàn toàn đường hô hấp trên trong khi ngủ dẫn đến hậu quả giảm thở hoặc ngưng thở hoàn toàn kèm theo những gắng sức hô hấp. OSAS là dạng phổ biến nhất của rối loạn hô hấp trong khi ngủ. ${ }^{2}$ Ở trẻ

Tác giả liên hệ: Nguyễn Ngọc Quỳnh Lê

Trường Đại học Y Hà Nội

Email: dr.quynhle@gmail.com

Ngày nhận: 02/12/2021

Ngày được chấp nhận: 13/12/2021 em, OSAS gặp ở 1 - 5\% trẻ em, cao nhất ở lứa tuổi 2 - 8 tuổi do liên quan đến sự phát triển của mô bạch huyết quanh đường hô hấp trên. ${ }^{2}$ Theo Hiệp hội Giấc ngủ Hoa kỳ, trẻ em được chẩn đoán OSAS nếu chỉ số ngưng thở - giảm thở (apnea- hypopnea index AHI) $\geq 1$ lần/ giờ. 2,3

Trong những năm gần đây, các tác giả nhận thấy rằng OSAS và $\mathrm{HPQ}$ đều là tình trạng viêm mạn tính đường thở, cùng chia sẻ các yếu tố nguy cơ và có mối liên quan mật thiết với nhau về cơ chế bệnh sinh. ${ }^{4,5,6}$ Tại Việt Nam, OSAS đã được một số tác giả đề cập đến nhưng chủ yếu trên người lớn. Do đó chúng tôi tiến hành đề tài "Đặc điểm lâm sàng, cận lâm sàng và chức năng hô hấp của trẻ hen phế quản có ngưng thở tắc nghẽn khi ngủ" với mục tiêu: Xác định tỷ lệ OSAS ở trẻ HPQ và mô tả đặc điểm lâm sàng, cận lâm sàng, chức năng hô hấp của trẻ HPQ có OSAS. 


\section{II. ĐÓI TƯƠ'NG VÀ PHƯƠNG PHÁP}

\section{1. Đối tượng}

Tất cả các trẻ được chẩn đoán $\mathrm{HPQ}$ đến khám và quản lý hen tại khoa Miễn dịch - Dị ứng - Khớp Bệnh viện Nhi Trung ương từ tháng 01/ 2021 đến tháng 10/2021.

\section{Tiêu chuẩn lựa chọn}

Trẻ từ 6 tuổi đến 17 tuổi, được chẩn đoán hen phế quản theo tiêu chuẩn GINA 2020 cho trẻ trên 5 tuổi. ${ }^{1}$ Trẻ có thể tham gia các xét nghiệm: đo chức năng hô hấp, test lẩy da, đa ký giấc ngủ. Cha mẹ và trẻ đồng ý tham gia nghiên cứu.

\section{Cõ' mẫu}

54 trẻ hen phế quản.

\section{Phương pháp}

Mô tả cắt ngang.

\section{Quy trình nghiên cứu}

Bước 1: Bệnh nhân hen đến khám có đủ tiêu chuẩn sẽ được mời vào nghiên cứu, khai thác bệnh sử, tiền sử theo mẫu bệnh án nghiên cứu, khám lâm sàng, phân độ amiđan theo thang Brodsky, chẩn đoán viêm mũi dị ứng theo tiêu chuẩn Hội viêm mũi dị ứng và ảnh hưởng lên bệnh hen (ARIA) 2020; xét nghiệm công thức máu, IgE toàn phần, test lẩy $\mathrm{da}$, đo nồng độ $\mathrm{F}_{\mathrm{E}} \mathrm{NO}$, đo chức năng hô hấp.

Test lẩy da: với các dị nguyên hô hấp như sau: Dp, Df, Blomia tropicalis, lông chó, mèo, gián. ${ }^{7}$ Test dương tính khi kích thước ban sẩn $\geq 3 \times 3 \mathrm{~mm}$.

Đo chức năng hô hấp: bằng máy đo Jaeger Vyntus ${ }^{\mathrm{TM}}$ IOS (CareFusion, Đức). ${ }^{7}$ Đánh giá kết quả rối loạn thông khí tắc nghẽn khi: $\mathrm{FEV}_{1}<80 \%, \mathrm{FEV}_{1} / \mathrm{FVC} \leq 70 \%$. Test phục hồi phế quản: dương tính nếu FEV1 tăng $\geq 12 \%$ so với trước khi hít Ventolin.

Đo nồng độ oxit nitrit trong hơ thở ra - $F_{E} N O$ : bằng máy đo cầm tay Hypair NO (Medisoft, Sorinnes, Belgium). Theo hướng dẫn của hội lồng ngực Mỹ, chỉ số $\mathrm{F}_{\mathrm{E}} \mathrm{NO}>20 \mathrm{ppb}$ là viêm đường thở tăng bạch cầu ái toan. ${ }^{8}$

Bước 2: Phân loại độ nặng của bệnh nhân theo GINA 2020.5

Bảng 1. Phân bậc mức độ nặng của hen phế quản

\begin{tabular}{cccccc}
\hline Bậc hen & $\begin{array}{c}\text { Triệu chứng } \\
\text { ban ngày }\end{array}$ & $\begin{array}{c}\text { Triệu chứng } \\
\text { ban đêm }\end{array}$ & $\begin{array}{c}\text { Mú́c độ cơn hen ảnh } \\
\text { hưởng đến hoạt động }\end{array}$ & PEF, FEV1 & $\begin{array}{c}\text { Dao động } \\
\text { PEF }\end{array}$ \\
\hline Bậc 1 & $<1$ lần/ tuần & $\leq 2$ lần/tháng & $\begin{array}{c}\text { Không giới hạn } \\
\text { hoạt đồng thể lực }\end{array}$ & $>80 \%$ & $<20 \%$ \\
\hline Bậc 2 & $\begin{array}{c}> \\
<1 \text { lần/tuần }\end{array}$ & $>2$ lần/tháng & $\begin{array}{c}\text { Có thể ảnh hưởng } \\
\text { hoạt động thể lực }\end{array}$ & $>80 \%$ & $20-30 \%$ \\
\hline Bậc 3 & Hàng ngày & $>1$ lần/tuần & $\begin{array}{c}\text { Ảnh hưởng hoạt động } \\
\text { thể lực }\end{array}$ & $60-80 \%$ & $>30 \%$ \\
\hline Bậc 4 & $\begin{array}{c}\text { Thường xuyên, } \\
\text { liên tục }\end{array}$ & Thường có & $\begin{array}{c}\text { Giới hạn hoạt động } \\
\text { thể lực }\end{array}$ & $<60 \%$ & $>30 \%$ \\
\hline
\end{tabular}

Bước 3: Đo đa ký hô hấp bằng máy đo Apnea Link ${ }^{\mathrm{TM}}$ Plus (ResMed, Australia). Chẩn đoán OSAS nếu chỉ số giảm- ngưng thở (apneahypopnea index $\mathrm{AHI}$ ) > 1 lần/ giờ .2,9 Chẩn đoán mức độ nặng của OSAS dựa vào chỉ số $A H I$ : Nhẹ: $A H I$ = 1 - 4 lần/ giờ; Vừa: $A H I=5$ - 9 lần/ giờ; Nặng: $A H I \geq 10$ lần /giờ. 


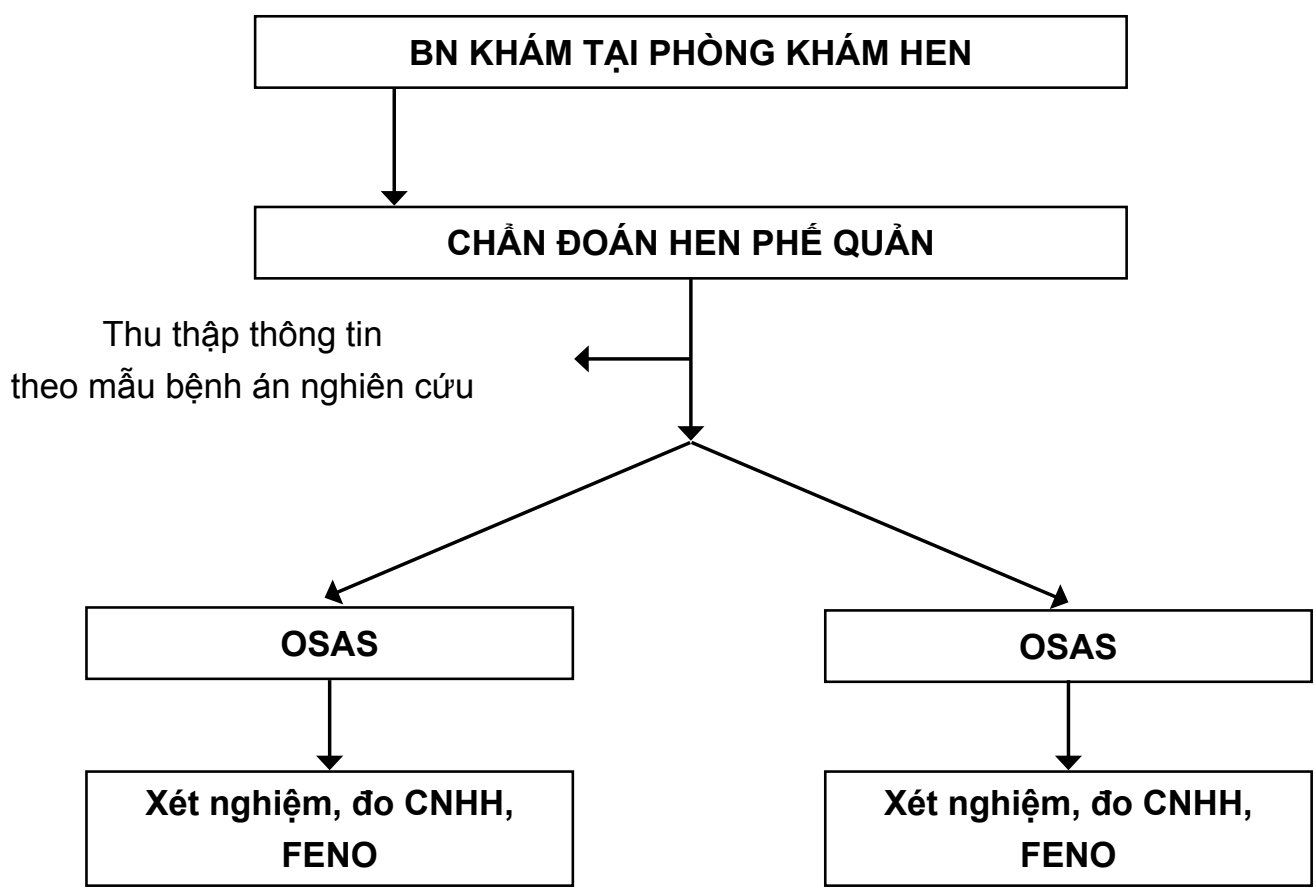

Hình 1. Sơ đồ nghiên cứu

\section{Xử lý số liệu}

Bằng phần mềm IBM-SPSS 22.0 (Chicago, USA) sử dụng các test: Chi- square test, Student's t test, One way ANOVA.

\section{4. Đạo đức nghiên cứu}

\section{KÉT QUẢ}

Nghiên cứu của chúng tôi thu thập được 54 bệnh nhân HPQ, trong đó 29 trẻ có mắc OSAS, xác định được tỷ lệ trẻ HPQ có OSAS là 53,7\%.

Bảng 2. Đặc điểm chung của đối tượng nghiên cứu

\begin{tabular}{|c|c|c|c|c|c|}
\hline \multicolumn{3}{|c|}{ Biến số } & $\begin{array}{c}\text { HPQ có OSAS } \\
(n=29)\end{array}$ & $\begin{array}{c}\text { HPQ không OSAS } \\
(n=25)\end{array}$ & $\mathbf{p}$ \\
\hline \multicolumn{3}{|c|}{ Tuổi, năm (trung bình \pm SD) } & $8,38 \pm 0,38$ & $8,26 \pm 0,19$ & $>0,05$ \\
\hline \multirow[t]{2}{*}{ Giới } & Nam & $\mathrm{n}(\%)$ & $18(62,0)$ & $18(72,0)$ & $>0,05$ \\
\hline & Nữ & $\mathrm{n}(\%)$ & $11(38,0)$ & $7(28,0)$ & \\
\hline \multicolumn{2}{|c|}{$\mathrm{BMI}, \mathrm{kg} / \mathrm{m}^{2}$} & & $17,23 \pm 2,95$ & $17,4 \pm 2,8$ & $>0,05$ \\
\hline \multicolumn{2}{|c|}{ Amiđan quá phát $\geq$ độ 2} & $\mathrm{n}(\%)$ & $8(27,6)$ & $9(36)$ & $>0,05$ \\
\hline \multicolumn{2}{|c|}{ Viêm mũi dị ứng } & $\mathrm{n}(\%)$ & $16(55,17)$ & $14(56)$ & $>0,05$ \\
\hline
\end{tabular}

Nghiên cứu đã được hội đồng Đạo đức Nghiên cứu $Y$ sinh học- trường Đại học $Y$ Hà Nội phê duyệt (Giấy chứng nhận chấp thuận khía cạnh đạo đức số 502/GCN-HĐĐĐNCYSHĐHYHN ngày 11/05/2021). 


\begin{tabular}{|c|c|c|c|c|c|}
\hline \multicolumn{3}{|c|}{ Biến số } & $\begin{array}{l}\text { HPQ có OSAS } \\
(n=29)\end{array}$ & $\begin{array}{l}\text { HPQ không OSAS } \\
(n=25)\end{array}$ & p \\
\hline Test lẩy $\mathrm{d}$ & tính & $\mathrm{n}(\%)$ & $21(72,41)$ & $20(80)$ & $>0,05$ \\
\hline \multirow{4}{*}{ Bậc hen } & Bậc 1 & n (\%) & $3(10,35)$ & $7(28)$ & \multirow{4}{*}{$>0,05$} \\
\hline & Bậc 2 & $\mathrm{n}(\%)$ & $10(34,48)$ & $9(36)$ & \\
\hline & Bậc 3 & $\mathrm{n}(\%)$ & $16(55,17)$ & $9(36)$ & \\
\hline & Bậc 4 & $\mathrm{n}(\%)$ & $0(0)$ & $0(0)$ & \\
\hline
\end{tabular}

Tuổi trung bình nhóm trẻ hen có OSAS là 8,38 $\pm 0,38$ tuổi, chủ yếu gặp ở nam. Nhóm trẻ hen có OSAS biểu hiện đồng mắc viêm mũi dị ứng là $55,17 \%$ và $27,6 \%$ trẻ có amiđan quá phát từ độ 2 trở lên. Nhóm hen có OSAS chủ yếu gặp hen bậc 2 và bậc 3 (tỷ lệ lần lượt $34,48 \%$ và $55,17 \%)$. Không có sự khác biệt giữa 2 nhóm về tuổi, giới, BMI, tỷ lệ viêm mũi dị ứng, amidan quá phát, bậc hen.

Bảng 3. Đặc điểm cận lâm sàng và chức năng hô hấp của trẻ HPQ có OSAS

\begin{tabular}{lccccc}
\hline \multirow{2}{*}{ Các thông số } & \multicolumn{2}{c}{$\begin{array}{c}\text { HPQ có OSAS } \\
(\mathbf{n}=\mathbf{2 9})\end{array}$} & $\begin{array}{c}\text { HPQ không OSAS } \\
(\mathbf{n = 2 5})\end{array}$ & p \\
\cline { 2 - 5 } & $\mathbf{n}$ & $\mathbf{G i a ́ ~ t r i ̣ ~}$ & $\mathbf{n}$ & Giá trị & \\
\hline Bạch cầu, G/L & 29 & $10,1 \pm 3,3$ & 25 & $8,4 \pm 1,2$ & $>0,05$ \\
\hline Bạch cầu ái toan, \% & 29 & $3,6 \pm 1,9$ & 25 & $6,6 \pm 4,9$ & $>0,05$ \\
\hline IgE, Ul/mL, trung vị & 29 & $594,7 \pm 76,5$ & 25 & $379,4 \pm 55,6$ & $<0,05$ \\
\hline FENO (ppb) & 29 & $21,55 \pm 19,0$ & 25 & $22,19 \pm 15,1$ & $>0,05$ \\
\hline FEV1- pre (\%) & 29 & $75,1 \pm 16,61$ & 25 & $82,64 \pm 15,1$ & $>0,05$ \\
\hline FEV1/FVC- pre (\%) & 29 & $68,8 \pm 11,75$ & 25 & $64,70 \pm 19,0$ & $>0,05$ \\
\hline PEF- pre (\%) & 29 & $69,12 \pm 16,2$ & 25 & $62,24 \pm 11,4$ & $>0,05$ \\
\hline
\end{tabular}

Nồng độ IgE máu ngoại vi của trẻ hen có OSAS là $594,7 \pm 76,5 \mathrm{lU} / \mathrm{mL}$ cao hơn có ý nghĩa thống kê so với nhóm hen đơn thuần $(379,4 \pm 55,6 \mathrm{IU} / \mathrm{mL})$ với $\mathrm{p}<0,05$. Chỉ số chất viêm đường thở FENO cao hơn chỉ số bình thường, tuy nhiên chưa ghi nhận sự khác biệt ở mức có ý nghĩa thống kê giữa hai nhóm.
Các chỉ số chức năng hô hấp trước nghiệm pháp phục hồi phế quản ở nhóm trẻ $\mathrm{HPQ}$ có OSAS và trẻ hen đơn thuần đều thấp hơn giá trị lý thuyết theo tuổi. Thể tích khí thở ra tối đa trong giây đầu tiên (FEV1) của nhóm hen có OSAS là $75,1 \pm 16,61 \%$ thấp hơn nhóm hen đơn thuần $(82,64 \pm 15,1 \%)$, tuy nhiên sự khác biệt chưa đạt mức ý nghĩa thống kê. 
Bảng 4. Chỉ số AHI ở bệnh nhân HPQ có OSAS

\begin{tabular}{ccc}
\hline Chỉ số AHI & $\mathbf{n}$ & Tỷ lệ (\%) \\
\hline Nhẹ & 17 & 58,62 \\
\hline Trung bình & 12 & 41,38 \\
\hline Nặng & 0 & 0,0 \\
\hline Tổng số & 29 & 100 \\
\hline
\end{tabular}

Trong số 29 bệnh nhân HPQ có OSAS, 58,62\% bệnh nhân có OSAS mức độ nhẹ (AHI: 1- 4 lần/ giờ), 41,18\% HPQ có OSAS trung bình (AHI: 5- 9 lần/ giờ), không có bệnh nhân OSAS mức độ nặng.

Bảng 5. Bảng phân bố chỉ số AHI theo bậc hen ở bệnh nhân HPQ có OSAS

\begin{tabular}{|c|c|c|c|c|c|c|}
\hline \multirow{2}{*}{$\begin{array}{l}\text { Chỉ số AHI } \\
\text { Bậc hen }\end{array}$} & \multicolumn{2}{|c|}{ Nhẹ } & \multicolumn{2}{|c|}{ Trung bình } & \multirow{2}{*}{ Tổng } & \multirow{2}{*}{$p$} \\
\hline & $n$ & Tỷ lệ \% & $\mathrm{n}$ & Tỷ lệ \% & & \\
\hline Bậc 1 & 3 & 10,35 & 0 & 0 & 3 & $>0,05$ \\
\hline Bậc 2 & 10 & 34,48 & 0 & 0 & 10 & $>0,05$ \\
\hline Bậc 3 & 4 & 13,79 & 12 & 41,38 & 16 & $<0,05$ \\
\hline Tổng & 17 & 58,62 & 12 & 41,38 & 29 & \\
\hline
\end{tabular}

Tỷ lệ OSAS trong nhóm hen bậc 1 thấp hơn so với tần suất gặp OSAS trong nhóm trẻ hen bậc 2 và bậc $3(10,35 \%$ so với $34,48 \%$ và $55,17 \%)$. Không có sự khác biệt có ý nghĩa thống kê về tỷ lệ OSAS mức độ nhẹ giữa ba

\section{BÀN LUẬN}

Trước đây, OSAS và $\mathrm{HPQ}$ được coi là hai bệnh riêng biệt, nhưng hiện nay nhiều bằng chứng cho thấy có mối liên quan mật thiết giữa $\mathrm{HPQ}$ và $O S A S$. Các nghiên cứu trên thế giới ghi nhận tỷ lệ OSAS ở trẻ HPQ ước tính khoảng $63 \%$, nguy cơ xuất hiện OSAS ở bệnh nhân hen cao gấp 2,51 lần so với nhóm chứng. ${ }^{5}$

Kết quả nghiên cứu của chúng tôi xác định được tỷ lệ trẻ mắc $\mathrm{HPQ}$ có OSAS là $53,7 \%$, trẻ nam gặp nhiều hơn trẻ nữ 1,6 lần (bảng 2). Kết quả này thấp hơn một nghiên cứu khác trên đối tượng trẻ hen của tác giả Nguyễn Hoàng Yến $(65,9 \%){ }^{4}$ Điều này có thể do tác giả Nguyễn nhóm hen bậc 1 , bậc 2 và bậc 3 (10,35\%; $34,48 \%$ và $13,79 \%)$. Nhóm trẻ hen bậc 3 có tỷ lệ OSAS mức độ trung bình cao hơn rõ rệt so với tỷ lệ OSAS mức độ nhẹ $(p<0,05)$.

Hoàng Yến nghiên cứu trên tất cả bệnh nhân hen từ 2- 17 tuổi, là lứa tuổi có tỷ lệ OSAS cao nhất do tình trạng phì đại amiđan và VA; còn đối tượng trong nghiên cứu của chúng tôi là trẻ trên 6 tuổi, lứa tuổi amiđan và VA bắt đầu thoái triển.

Hen và OSAS có thể cùng tồn tại gây ra hội chứng chồng lấp, trong đó mối quan hệ hai chiều có thể ảnh hưởng xấu đến nhau. Hai bệnh đều chịu ảnh hưởng của quá trình viêm mạn tính đường thở, yếu tố nguy cơ như béo phì, viêm mũi dị ứng, trào ngược dạ dày- thực quản... Các tác giả đều kết luận viêm đường hô hấp trên và thiếu oxy gián đoạn khi ngủ ảnh 
hưởng đến biểu hiện và mức độ nghiêm trọng của bệnh đường hô hấp dưới như hen HPQ. ${ }^{2}$

Yếu tố dị ứng là một đặc điểm chuyên biệt của phân loại kiểu hình HPQ. ${ }^{12}$ Trong nghiên cứu của chúng tôi có $55,17 \%$ trẻ $\mathrm{HPQ}$ có OSAS đồng mắc viêm mũi dị ứng. Kết quả này cho thấy viêm mũi dị ứng là yếu tố nguy cơ của $H P Q$ và OSAS tương đồng với nghiên cứu của tác giả Damianaki. ${ }^{5}$ Đặc biệt là $H P Q$ và viêm mũi dị ứng có mối liên quan chặt chẽ với nhau vì cùng có chung sinh bệnh học và phản ứng viêm đường hô hấp. ${ }^{11}$ Về cơ chế bệnh sinh, khi ngủ khoang mũi hoạt động như đường dẫn khí chính; khi mũi viêm gây xung huyết niêm mạc, phù nề, hẹp mũi gây hẹp đường hô hấp trên. Sự kích thích của hiện tượng viêm mãn tính niêm mạc có thể dẫn đến phản xạ co thắt phế quản thông qua phản xạ đối giao cảm mũi - phế quản. Bên cạnh đó việc thay thế thở bằng miệng khi mũi bị tắc nghẽn dẫn đến không khí khô đi vào đường hô hấp dễ gây ra cơn hen. Bệnh nhân HPQ kèm theo viêm mũi dị ứng bị OSAS cao hơn nhóm không bị viêm mũi dị ứng. ${ }^{11}$

Trong 29 bệnh nhân hen có OSAS, chúng tôi gặp chủ yếu là HPQ bậc 2 và bậc 3 (34,48\% và $55,17 \%$ ). Trong khi đó, HPQ bậc 1 chiếm tỷ lệ thấp $10,35 \%$ và nghiên cứu của chúng tôi không gặp bệnh nhân HPQ bậc 4 . Kết quả này tương đồng với một số nghiên cứu khác. ${ }^{2,5}$ Điều này có thể do các tiến bộ về chẩn đoán và kiểm soát hen nhưng cũng có thể do hen nặng và hen khó trị ở trẻ em chiếm tỷ lệ thấp. ${ }^{12}$

Các nghiên cứu trong y văn cho thấy những trẻ OSAS có chỉ số $\mathrm{AHI}$ cao thì có nguy cơ mắc hen cao hơn. ${ }^{6}$ Tác giả Alharbi thấy rằng trẻ OSAS tăng nguy cơ mắc $\mathrm{HPQ}$ cao hơn $35 \%$ so với nhóm trẻ không có OSAS. ${ }^{6}$ Tuy nhiên trong nghiên cứu của chúng tôi không tìm thấy sự khác biệt có ý nghĩa thống kê về phân bố bậc hen giữa 2 nhóm trẻ hen đơn thuần và $\mathrm{HPQ}$ có OSAS. Điều này có thể do cỡ mẫu của chúng tôi nhỏ, do đó cần các nghiên cứu kéo dài với số lượng bệnh nhân lớn hơn để đánh giá về mối liên quan này.

Một trong những thăm dò cận lâm sàng chủ yếu ở trẻ em và người lớn bị $\mathrm{HPQ}$ là đo chức năng hô hấp, đây là một phương pháp được sử dụng phổ biến trong chẩn đoán, phân loại mức độ nặng và theo dõi điều trị hen với độ đặc hiệu cao. ${ }^{1}$ Trẻ hen có OSAS trong nghiên cứu có giá trị FEV1 trung bình là $75,1 \pm 16,61 \%$, thấp dưới $80 \%$ giá trị lý thuyết. Kết quả này thấp hơn các chỉ số tương ứng trong nghiên cứu trước, ${ }^{4}$ có thể do chúng tôi có nhiều bệnh nhân hen trung bình hơn. Các chỉ số FEV1/ FVC và PEF của nhóm bệnh nhân hen có OSAS cũng giảm dưới $80 \%$ giá trị lý thuyết.

Trong nghiên cứu, tỷ lệ trẻ hen có OSAS dương tính với một dị nguyên hô hấp là $72,41 \%$, thường gặp nhất là $D$.farinae và D.pteronyssius. Dị ứng với biểu bì lông súc vật như chó, mèo gặp với tỉ lệ không cao. Kết quả này tương tự nghiên cứu trước đây cho thấy D.pteronyssinus là dị nguyên phổ biến ở bệnh nhân $\mathrm{HPQ}$ và viêm mũi dị ứng. ${ }^{13}$ Kiểm soát môi trường trong nhà là một yếu tố quan trọng để loại bỏ yếu tố kích thích khởi phát cơn hen và cải thiện kết quả điều trị hen.

Theo hội Lồng ngực Mỹ, đo nồng độ oxit nitrit trong hơi thở ra ở phế quản (FENO) là một kỹ thuật không xâm lấn, dễ thực hiện, an toàn với độ tin cậy cao để phản ánh tình trạng viêm tăng bạch cầu ái toan và được sử dụng như chất chỉ điểm sinh học đánh giá viêm trong hen. ${ }^{8}$ FENO có mối liên quan chặt chẽ với bạch cầu ái toan trong máu, bạch cầu ái toan trong đờm, trong dịch rửa phế quản hay trong sinh thiết phổi. Trong nghiên cứu của chúng tôi

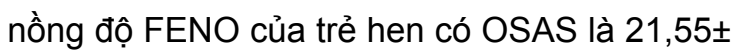
19,0 ppb, phù hợp với các nghiên cứu trước đây trên trẻ HPQ. ${ }^{10}$ Tuy nhiên chúng tôi không tìm thấy sự khác biệt về các đặc điểm cận lâm 
sàng khác giữa nhóm hen có OSAS và nhóm $\mathrm{HPQ}$ đơn thuần. Cần những nghiên cứu với số lượng bệnh nhân lớn hơn để tiếp tục đánh giá về các chỉ số cận lâm sàng trên.

Phân tích về mức độ hen và OSAS, chúng tôi nhận thấy 58,62\% trẻ HPQ có OSAS ở mức độ nhẹ, 41,38\% trẻ hen mắc OSAS ở mức độ trung bình, không có trẻ OSAS nặng, kết quả này tương đồng với nghiên cứu khác. ${ }^{4}$ Điều này cho thấy khác với người lớn, trẻ em thường mắc OSAS ở mức độ nhẹ, có thể do trẻ em ít có các yếu tố nguy cơ và bệnh đồng mắc gây OSAS nặng như người lớn. Nếu được chẩn đoán và điều trị kịp thời OSAS ở trẻ em có thể hồi phục hoàn toàn.

Nghiên cứu của chúng tôi thấy rằng OSAS mức độ trung bình gặp chủ yếu trong nhóm trẻ hen bậc 3 . Điều này khá phù hợp với kết quả của các nghiên cứu trên thế giới cho thấy 95\% trẻ hen nặng có OSAS. ${ }^{5}$ OSAS làm tăng mức độ nặng và giảm mức độ kiểm soát hen, ngược lại $\mathrm{HPQ}$ làm tăng nguy cơ xuất hiện OSAS. ${ }^{5}$ Trẻ mắc cả hai bệnh hen và OSAS có chất lượng giấc ngủ kém, tăng nguy cơ biến chứng tim mạch, chuyển hóa, thần kinh...

\section{KÉT LUÂN}

Tỷ lệ hen phế quản có mắc OSAS khi ngủ ở trẻ trên 6 tuổi là $53,7 \%$, chủ yếu ở mức độ nhẹ và trung bình. Trẻ hen bậc 3 có xu hướng mắc OSAS khi ngủ ở mức độ nặng hơn so với trẻ hen nhẹ. Phần lớn trẻ hen có OSAS đồng mắc viêm mũi dị ứng và có đáp ứng viêm qua trung gian Th2 thể hiện qua chỉ số FENO tăng. Những kết quả thu được cho thấy cần phải quan tâm đến chẩn đoán OSAS ở trẻ hen phế quản và phối hợp điều trị trong chiến lược kiểm soát hen ở nhóm trẻ này.

\section{TÀI LIẸU THAM KHẢO}

1. Global Initiative for asthma. Global Strat- egy for Asthma Management and Prevention. 2020. p. 1-27.

2. Al-Shamrani A, Alharbi AS. Diagnosis and management of childhood sleep-disordered breathing. Clinical approach. Saudi Med J. 2020; 41(9): 916-929.

3. Kapur VK, Auckley DH, Chowdhuri S et al. Clinical Practice Guideline for Diagnostic Testing for Adult Obstructive Sleep Apnea: An American Academy of Sleep Medicine Clinical Practice Guideline. J Clin Sleep Med. 2017 Mar 15;13(3):479-504

4. Nguyen-Hoang $\mathrm{Y}$, Nguyen-Thi-Dieu T, Duong-Quy S. Study of the clinical and functional characteristics of asthmatic children with obstructive sleep apnea. J Asthma Allergy. 2017; 10: 285-292.

5. Damianaki A, Vagiakis E, Sigala l et al. The Co- existence of Obstructive Sleep Apnea and Bronchial Asthma: Revelation of a New Asthma Phenotype? J.Clin.Med. 2019; 8(9),1476.

6. Alharbi M, Almutairi A, Alotaibi D et al. The prevalence of asthma in patients with obstructive sleep apnoea. Prim. Care Respir. J. 2009, 18, 328-330. 15.

7. Lê Thị Tuyết Lan, Trần Văn Ngọc. Hình ảnh học và thăm dò chức năng hô hấp.2016. Nhà xuất bản y học, Hà Nội.

8. Duong-Quy S. Clinical Utility Of The Exhaled Nitric Oxide (NO) Measurement With Portable Devices In The Management Of Allergic Airway Inflammation And Asthma. J Asthma Allergy. 2019 Oct 7;12:331-341.

9. Bộ Y tế. Đo đa ký hô hấp. Hướng dẫn quy trình kỹ thuật nội khoa chuyên ngành hô hấp. Nhà xuất bản Y học, 2016. Tr 267-270.

10. Nguyen-Thi-Bich $\mathrm{H}$, Duong-Thi-Ly $H$, Thom VT et al. Study of the correlations between fractional exhaled nitric oxide in exhaled breath and atopic status, blood 
eosinophils, FCER2 mutation, and asthma control in Vietnamese children. J Asthma Allergy. 2016 Sep 14;9:163-170.

11. Ferrando M, Braido F, Baiardini I et al. Prevalence and impact of rhinitis, sleep disordered breathing and OSA in asthmatic patients. Shortness of Breath. 2014; 2. 125-130.

12. Covar RA, Fuhlbrigge AL, Williams $P$ et al. The Childhood Asthma Management
Program (CAMP): contributions to the understanding of therapy and the natural history of childhood asthma. Curr Respir Care Rep.2012; 1, 243-250.

13. Đào Thị Hồng Diên, Lê Thị Minh Hương, Nguyễn Thị Diệu Thúy. Nghiên cứu kết quả test lảy da với các dị nguyên hô hấp trong nhà của bệnh nhi hen phế quản. Tạp chí $Y$ học thực hành. 2013; 860, số 3/2013: 52-55.

\section{Summary}

\section{CLINICAL CHARACTERISTICS, LABORATORY TESTS AND SPIROMETRY OF ASTHMATIC CHILDREN WITH OBSTRUCTIVE SLEEP APNEA}

Inflammation disease of the airway such as obstructive sleep apnea and asthma are linked with each other. We conducted a cross-sectional descriptive examination on 54 asthmatic children from 6 to 17 years old, managed at the National Children's Hospital to determine the rate of obstructive sleep apnea and describe the clinical and subclinical characteristics of this special group. Obstructive sleep apnea was diagnosed by respiratory polygraphy. $29 / 54$ (53.7\%) asthmatic children of 8.38 years old have obstructive sleep apnea, of which $26 / 29(89.65 \%)$ children had mild and moderate persistent asthma with increased FENO (21.55 \pm 19).0 ppb). 17/29 (58.62\%) asthmatic children had mild obstructive sleep apnea, moderate persistent asthmatic children had higher prevalence of moderate obstructive sleep apnea $(41.38 \%$ vs $13.79 \%, p<0.05)$. OSA diagnosis and treatment is essential for the management of asthmatic children.

Keywords: Asthma, OSAS, FENO, children. 